\title{
The Relationship between Entrepreneurship and Unemployment in the Business Cycle
}

\author{
Prof. dr hab. Aleksandra Gaweł \\ Department of Microeconomics \\ Poznań University of Economics \\ aleksandra.gawel@ue.poznan.pl
}

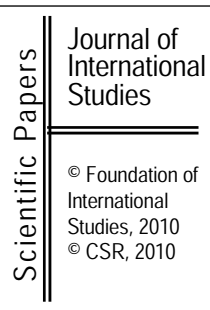

\begin{abstract}
Connections between the situation in the labour market and entrepreneurship are of at least two kinds. Firstly, the situation on the labour market, especially connected with unemployment, is often treated as negative motivation for entrepreneurial undertakings according to recessional push theory. Secondly, labour is one of the production factors, so paid workers influence entrepreneurship through the possibility of enterprise growth. To investigate this relationship, entrepreneurs are divided into two groups, self-employed persons (entrepreneurs without any workers), and proper entrepreneurs (entrepreneurs who employ paid workers). The context of business cycle as time perspective is used. Two hypotheses are tested. Firstly, the cyclical changes in activity of selfemployment and proper entrepreneurship react differently on the fluctuations in reference cycle, the fluctuations of self-employment are countercyclical, and the fluctuations of proper entrepreneurship are procyclical. Secondly, the cyclical changes of unemployment and wages influence on the fluctuations of self-employment as negative motivation while on the fluctuations of proper entrepreneurship as production factor. These hypotheses received positive verification based on time series for Poland, covering the years 1993-2009.
\end{abstract}

Keywords: entrepreneurship, entrepreneurial motivation, occupational choice, business cycle.

JEL classification: L26, J62, E32.

\section{Introduction}

Entrepreneurs play a double role in the economy, especially in the labour market. Firstly, entrepreneurship can be treated as a form of economic activity, as opposed to the workers. According to the theory of occupational choice, everyone can choose a form of economic activity between being an entrepreneur or a paid worker. Entrepreneurs receive the entrepreneurial profits of risk; workers receive salaries without risk. In this context, choosing entrepreneurship is connected with leaving the labour market. There seems to be an empirical relationship between an increase in the entrepreneurial rate and a decrease in the employment rate. Moreover, according to the theory of a recessional push toward entrepreneurship, an unfavorable situation in the labour market can create a push towards entrepreneurship through negative motivation. In this case, an increase in the entrepreneurial rate is caused by an 
increase in the unemployment rate.

Secondly, entrepreneurs are agents who decide on the utilisation of production factors, labour and financial capital. The growth of enterprises managed by entrepreneurs is connected to their need to employ workers. In this case, a higher level of activity by entrepreneurs leads to a higher level of paid employment and a lower level of unemployment.

\section{Entrepreneurship and the labour market}

One well-known theory of entrepreneurship, the occupational choice theory, treats being an entrepreneur as one form of professional activity, which is an alternative to being an employee. A given individual takes a decision on becoming an entrepreneur or an employee in a rational way, using all the available information to make the most profit from the chosen form of activity. An individual becomes an entrepreneur when his subjective relative entrepreneurial profit is positive as compared with the profit from other forms of economic activity (Minniti, Bygrave 1999). Generally speaking, a given individual chooses entrepreneurship instead of working as hired labour in order to maximize their usefulness, although how to determine usefulness is a debatable question.

One of the best-known determinants of occupational choice is a person's attitude towards risk. This factor was initially indicated in the model proposed by Kihlstrom and Laffont (1979) and later on developed by, among others, Banerjee and Newman (1993). Employees receive a risk-free salary as hired labour, whereas entrepreneurs obtain a profit through bearing the risk of failure. Many factors influence a person's choice of economic activity; the most important of these being entrepreneurial abilities, professional skills, attitude to risk and access to start-up capital. The model, however, concentrates on a person's attitude to risk considered as the crucial determinant of entrepreneurship. Individuals who are prone to take risks engage in business activities even when they expect less profit, which is not the case for risk-averse people.

Extensions to the occupational choice theory introduce into the model additional variables, which affect the start-up decision making process, such as f.e an access to financial capital. In models of liquidity constraint the probability of becoming an entrepreneur depends proportionally to whether a given person possesses the capital resources indispensable to start up and run an enterprise (e.g. Blanchflower, Oswald 1998; Holtz - Eakin et al. 1994) because of financial market imperfections, where moral hazard is the dominant source of these imperfections (Paulson and et. 2006).

Another factor influencing occupational choice is the situation in the labour market as regards wages, labour demand and supply. The occupational choice depends on the relationship between wages accessible in the labour market and potential profits from entrepreneurial activity (Blau 1987). A person will undertake entrepreneurial activity if the potential profits from running their own business in relation to profits from hired work are higher than the non-profit value of entrepreneurship and hired work (Bernhardt 1994; Taylor 1996). The profit rate of companies is one of the most important determinants of start-up rate (Naudé et al. 2008).

Another element in the labour market situation which influences the decision to become an entrepreneur is disequilibrium between demand and supply of labour. Such imbalances affect the quantity and quality of the jobs offered and the opportunities to find a job as an alternative occupational choice to entrepreneurship. According to empirical findings the propensity to take up self-employment is higher for males, unemployed people and those with past entrepreneurial experience, who live in more densely populated and faster growing regions with higher rates of new firm formation (Wagner, Sternberg 2004). 
The results of empirical studies concerning entrepreneurial motivation have made it possible to formulate two hypotheses, commonly referred to as push and pull theories of entrepreneurial motivation. Theories of the recessional push assume that individuals are pushed into entrepreneurship by negative situations in the labour market, for instance by the loss of a job and the virtual impossibility of finding a new one, or a lack of satisfaction in an existing job. Such negative factors connected with the situation in the labour market activate people's entrepreneurial talents. On the other hand, the pull theories state that attractive and potentially profitable business opportunities attract individuals into entrepreneurial activity; thus a given person becomes an entrepreneur as a result of the positive effects of economic stimuli. This is the basis to distinguish between opportunity entrepreneurs and necessity entrepreneurs (Thurik et al. 2008; Block, Koellinger, 2009). The kind of entrepreneurial motivation can affect on the entrepreneurial aspirations. For example, necessity entrepreneurs are less oriented towards innovation and growth (Hessels and et. 2008).

Some empirical studies, however, indicate that both theories (recessional-push and prosperity-pull) do not have to be treated as competitors because it is the joint influence of both groups of factors which decides on the level of entrepreneurial activity (Gilad, Levine 1986). Empirical research does not decisively answer the question as to which type of motivation is predominant. It has been proved in interdisciplinary questionnaire studies (Korunka et al. 2003) that one third of entrepreneurs starting a business were earlier unemployed, and it was not so much their own willingness as economic pressure that pushed them into entrepreneurial activity. At the same time, comparative studies of the factors affecting a choice between hired labour and self-employment (Morawski, Socha 2003) indicate that better opportunities for hired labour may be a significant factor behind the rate of self-employment in Germany and Great Britain being lower than in Poland.

Negative labour market-related factors pushing people into entrepreneurship include the loss of a job or the threat of losing a job, which may be a direct stimulus for a person to start entrepreneurial activity. Studies on two groups of people who started their own businesses, who had previously been hired workers or unemployed, show that even negative motivation did not influence the standard of their firms. The founders of both groups of businesses achieved a comparable rate of survival for their firms in the market and a comparable rate of growth (Hinz, Jungbauer-Gans 1999).

The relationship between unemployment and a propensity to undertake entrepreneurial activity is also explained by using the standard search model. Unemployed people looking for jobs decide on the lowest wages they are willing to accept. Due to the costs related to looking for a job, e.g. correspondence and job interviews, the longer a person is unemployed and in search of a job the lower will be their wage threshold, which means that their remuneration expectations decrease. An unemployed person will stop looking for a job and choose to become an entrepreneur when the expected income from being hired labour falls below the expected income from entrepreneurship. Thus, the longer a given person remains unemployed the higher the probability that they will take up entrepreneurial activity; because the expected remuneration from hired labour, as compared to the costs of running one's own business, decreases (Alba- Ramirez 1994).

When analyzing the relationship between the labour market and entrepreneurship the problem of human capital should also be mentioned. From the theoretical point of view, the financial and human capital of an entrepreneur are the factors behind new company creation. But the ideas and intentions of entrepreneurs shape the initial strategy of new firms and they are the main factors in its growth (Bird 1988). According to some research results, financial constraints are much less important than the human capital of an entrepreneur in new firm creation (Uusitalo 2001). The human capital of an entrepreneur is also the most important factor behind new company survival (Cressy 1996), and at the same time it influences the 
structure of financial capital usage and the level of profit (Bates 1990, 1985). Entrepreneurial innovativeness depends on individual factors such as f.e. high educational attainment or unemployment (Koellinger 2008).

In the context of entrepreneurship, human capital can be divided into two groups; general human capital (i.e. education and work experience) and entrepreneur-specific human capital (i.e. business ownership experience, managerial abilities, entrepreneurial capabilities). Entrepreneur-specific rather than general human capital is most important for business opportunity identification (Ucbasaran and et. 2008).

Putting all these facts together, an increase in the unemployment rate is a factor which influences increases in the entrepreneurship rate for two reasons. Firstly, it can constitute negative motivation for undertaking entrepreneurial activity according to the recessional push theory. Secondly, this can also be related to the fact that an increase in unemployment means that the conditions for hiring new workers are better for entrepreneurs, which can stimulate the growth of companies and entrepreneurial activity.

Another problem is connected to various theoretical controversies regarding the definition of an entrepreneur. These controversies cause difficulty when conducting empirical studies because there is no generally accepted measure of entrepreneurship. Doubts of a theoretical nature aside, a large number of empirical studies identify an entrepreneur as a selfemployed person, i.e. somebody who conducts economic activities on their own account.

Controversies as to whether it is correct to identify an entrepreneur as a self-employed person may result from the differences in definition of entrepreneurs themselves. Namely, if in any definition of entrepreneur an emphasis is placed on their ability to take risks, then a self-employed person may be treated as an entrepreneur because they are not a hired worker who receives a risk-free wage for their work but undertakes the risk of conducting economic activity and obtains a risk-bound profit. If, however, the ability to introduce innovations is considered as the main feature of entrepreneurs, then identifying a self-employed person as an entrepreneur is ambiguous because the people who introduce innovations may be both selfemployed or hired workers. One certainly cannot automatically identify a self-employed person as an innovator (Lindh, Ohlsson 1996), but the view can be accepted that the risks relating to independent economic activity frequently encompass searching for new methods of production, organizational solutions and markets.

\section{Hypotheses of entrepreneurial relationships with labour markets and their theoretical explanation}

In this paper the accepted definition of an entrepreneur is a person capable of taking risks and conducting entrepreneurial activity, therefore entrepreneurs are identified with selfemployed people. The self-employment rate is treated as the best available entrepreneurial measure across-countries and over time (Acs et al. 2009). To describe the relationship between entrepreneurship and the labour market, two assumptions are made. Firstly, entrepreneurs are divided into two groups. The first group is composed of self-employed people, entrepreneurs who do not employ any workers. The second group, the so called proper entrepreneurs, includes entrepreneurs who employ paid workers, those who are employers (e.g. Abell, Crouchley, Mills 2001). This division seems to be particularly important in the context of the influence of labour market pressures. It can be supposed that the reaction of self-employed to the labour market situation is connected with their attitude towards paid work as an alternative to being economically active by running their own company. For proper entrepreneurs, the situation in the labour market determines the availability and costs of hiring workers in the context of labour as a production factor. 
The second assumption is connected with the time perspective and various kinds of fluctuation in the economy. Dynamic processes in the economy are under the simultaneous influences of different time horizon factors, i.e. growth tendencies, seasonal fluctuations, business cycle fluctuations and random fluctuations (e.g. Flaig 2003). These characteristics of economic phenomena are responsible for the fact that an empirical analysis should refer to a certain time horizon. In presented paper a business cycle perspective is accepted, where business cycles are understood as more or less regular fluctuations of economic activity that affect all parts of the economy and which occur in different economic sectors in a similar way (Ralf 2000, 7).

Initially, the business cycle was defined as the kind of fluctuations that consisted of periods of expansion, crisis, stagnation and revival occurring at the same time in many sectors of an economy. Because of the stable though undulatory growth of contemporary economies after World War II, the generally accepted definition of business cycles indicates that business cycles are deviations from long-term trends (Kydland, Prescott 1990). During recovery, the economy is at higher level than the long-term growth trend indicates, while recession is synonymous with the state of an economy below its long-term growth trend. The causes behind the existence of the business cycle are still under discussion. Initially, business cycles were treated as the result of internal mechanisms within an economy, though currently the importance of random supply or demand shocks hitting an economy that contribute to the occurrence of such cycles is stressed more often (Chatterjee 2000).

Contemporary business cycles are characterized by a number of regularities. The most important feature is that business cycles occur in all aspects of economic life, influencing the conditions of companies and consumers, employers and employees, product markets and financial markets. International synchronization of business cycles is also visible and economic variables are characterized by a constant sequence of fluctuations. Some of these variables are procyclical, which means that they increase during the recovery phase of the business cycle and decrease during the recessionary phase. Other variables are countercyclical, an economic recovery brings about a reduction, and a recession contributes to its growth.

According to conventional ideas about the business cycle, changes in consumption, investment, import and export, as well as total employment are procyclical; while changes in unemployment are countercyclical (Senhadji 2003; Ralf 2000, 22). This means that during a recovery the number and quality of business opportunities for entrepreneurs increase because of the growth in consumption and investment, as well as the labour market situation being better for employees. During a depression business opportunities decline and the labour market situation is worse for workers.

Based on the above mentioned assumptions, two hypotheses are tested.

Hypothesis 1: The cyclical changes in activity of self-employment and proper entrepreneurship react differently on the fluctuations in reference cycle. The fluctuations of self-employment are countercyclical, and the fluctuations of proper entrepreneurship are procyclical.

Hypothesis 2: The cyclical changes of unemployment and wages influence on the fluctuations of self-employment as negative motivation while on the fluctuations of proper entrepreneurship as production factor.

It is assumed that each person has three occupational choice options: being a paid worker, self-employed or proper entrepreneur. Each of these forms of economic activity bring particular benefits and entail specific costs. The benefits may be financial, in the form of profits or wages; or non-financial, such as job satisfaction; or the social position achieved. The costs of occupational activity include the effort involved in it as well as the human capital, and in the case of entrepreneurs also the financial capital employed. Every 
occupational choice entails certain alternative costs in the form of the possibilities of deriving benefit from other forms of activity. Potential remuneration for work is an alternative cost of being an entrepreneur, whereas potential entrepreneurial profit is an alternative cost of hired work.

Paid workers receive a wage for their work, a wage that is risk-free without any uncertainty about its value and the date of receipt. This wage is a kind of benefit for the effort and human capital of the worker involved in the job. The financial benefit of a self-employed is entrepreneurial profit, bound up with the risk of failure. A self-employed invests effort as well as their human and financial capital in running a business, while facing the risk of failure relating to obtaining a profit as well as not knowing its value and the time frame involved. A proper entrepreneur invests in their work both their own effort and human capital as well as the effort and human capital of their employees. Additionally, they invest their financial capital. The entrepreneurial profit of a proper entrepreneur is bound up with the risk of failure. Similarly to the case of a self-employed, the likelihood of making a profit or a loss is unknown, as is the value of the potential profit and the time frame involved.

The likelihood of making a profit or a loss depends on a variety of factors, but this article assumes that it is dependent on the business opportunities existing in an economy. The number and potential profitability of these opportunities change over the business cycle. During the recovery the dynamics of the economic aggregates such as consumption, investment or individual and corporate earnings increases, which contributes to an increase in both the number and the profitability of business opportunities. Thus the likelihood of achieving entrepreneurial profit is higher during the recovery. During the recession business opportunities decrease due to the decline in the dynamics of the fundamental economic aggregates, so the likelihood of achieving entrepreneurial profit is lower during this period.

Occupational choices are constantly revised depending on the changing conditions and transference occurs between the three forms of occupational activity. Hired workers abandon their positions and become self-employed, creating a job only for themselves; or proper entrepreneurs, employing other workers. Self-employed persons may progress to hiring labour or employing workers, thus becoming proper entrepreneurs. Proper entrepreneurs may dismiss their employees, thus becoming self-employed, or close down their business and become employees themselves.

Different scenarios of transference between the three occupational choices are therefore possible. Newly-employed workers may be former entrepreneurs or people who were previously unemployed or occupationally passive, for example those entering the job market for the first time. People who become self-employed may have previously been hired workers, proper entrepreneurs who closed down their business, unemployed or occupationally passive. And proper entrepreneurs may be former employees, self-employed who employed workers, or people who for various reasons did not work before.

\section{Results of empirical research into entrepreneurship and the labour market}

To verify the hypotheses on the relationship between entrepreneurship and the labour market, an empirical analysis of the time series was conducted. The rates of entrepreneurship were analysed. The related literature mentions three methods of calculating the denominator for the rate of entrepreneurship: size of the population, most frequently limited to the number of people of productive age; labour resources, i.e. the number of professionally active people amounting to the sum of the employed and unemployed; as well as the number of working people (Blanchlower 2000). In this paper one of the denominators of activity rates - labour resources - was accepted. As a result of all this, two dependent variables were developed: 
- rate of self-employed in the non-agricultural sector in terms of labour resources (RSE),

- rate of proper entrepreneurship (entrepreneurs with employees) in the nonagricultural sector in terms of labour resources (RPE).

In order to analyze the influence of the business cycle, a reference cycle should be established. Because it is often claimed that the business cycle is connected with fluctuations in manufacturing, sold production of manufacturing was taken as a reference cycle (REF).

The variables which illustrate the situation in the unemployment represent both the resource and the flow approach. It was assumed that the rate of long-term unemployed people who remain jobless for over 12 months in the total number of the unemployed represents the resource approach to unemployment, whereas the rates of newly registered and signed off unemployed people in the total number of the unemployed are linked with the flow approach. Another variable of the labour market taken into account is the average monthly wages in the enterprise sector. Average wages are an alternative benefit to entrepreneurial profit on the one hand, and the cost of hiring workers on the other. In this case, four labour market variables were taken into account:

- rate of the newly registered unemployed in total unemployment (RNU),

- rate of the signed off unemployed in total unemployment (RSU),

- rate of long-term unemployment in total unemployment (RLU),

- average monthly wages in enterprise sector (WAGE).

To recapitulate, the influence of the variables (REF), (RNU), (RSU), (RLU), (WAGE) on the variables (RSE), (RPE) was analysed. The following statistical publications were used as the primary sources of data in the analysis: Labour Force Survey in Poland published by the Central Statistical Office in Warsaw for the data concerning the occupational activity of the population, and Statistical Bulletin published by the Central Statistical Office in Warsaw for the data concerning the situation in the labour market and the reference cycle. All the data relates to the situation in Poland during the years 1993-2009.

To extract business fluctuations from the raw statistical time series data, several research steps were taken. First, in order to linearize the non-linear relationships, all the time series were converted into natural logarithms. Next, the time series were put through the procedure of seasonal decomposition by the CENSUS X-11 method and cleared of any influence of seasonal and random fluctuations. Thanks to this the time series obtained were subject to the joint influence of a development tendency and business cycle fluctuations, the so called Henderson curve. Then, a stochastic trend was differentiated by means of the Hodrick-Prescott filter ${ }^{1}$. Business cycle fluctuations were identified as percentage deviations of the Henderson curve from the trend.

After the analysis of the stationary character of the time series by means of a DickeyFuller unit-root test, Granger's causality analysis between particular pairs of variables was applied in order to identify the possible time lags between the explaining and explained variables (see Table 1 in the statistical appendix). The assumption was made that the maximum possible period of leads in the causality analysis is 8 periods, i.e. two years. Longer leads seem to have a lesser influence on making economic decisions and on the dependencies between economic magnitudes.

The results of Granger's causality indicate that not all pressures coming from the labour market during the business cycle can influence the rates of entrepreneurship. In three cases there were no grounds to reject the following zero hypotheses (RSU, RLU and WAGE do not Granger cause RSE). These relationships were not taken into consideration in subsequent research steps. Zero hypotheses for the remaining variables pairs were rejected,

\footnotetext{
${ }^{1}$ This filter is commonly used to determine a trend (Ravn, Uhlig, 2001).
} 
but with different time lags.

Next, the estimations of the parameters and fit of the regression function between dependent and independent variables of the model are realized in order to finally verify the relationships between the variables and their directions. The dependent variables were the rates of self-employment and proper entrepreneurship; whereas the independent variables were the reference cycle, rate of newly registered unemployed, rate of signed off unemployed, rate of long-term unemployment and average wages in the enterprise sector. The initial form of the regression function took into account the independent variables with all the leads which were significant from the viewpoint of causality.

Next, from the initial form of the regression functions statistically insignificant independent variables were removed in order to obtain regression functions of the parameters convergent with equations (1) to (4).

$$
\begin{gathered}
\mathrm{RSE}_{\mathrm{t}}=154,79+0,26 \mathrm{RNU}_{\mathrm{t}-2}-0,81 \mathrm{REF}_{\mathrm{t}} \\
\mathrm{RPE}_{\mathrm{t}}=-77,42+0,42 \mathrm{RNU}_{\mathrm{t}}+0,06 \mathrm{RSU}_{\mathrm{t}-2}+1,30 \mathrm{REF}_{\mathrm{t}-1} \\
\mathrm{RPE}_{\mathrm{t}}=13,83-1,93 \mathrm{WAGE}_{\mathrm{t}-1}+2,8 \mathrm{REF}_{\mathrm{t}-1} \\
\mathrm{RPE}_{\mathrm{t}}=-268,95+1,38 \mathrm{RLU}_{\mathrm{t}-4}+2,31 \mathrm{REF}_{\mathrm{t}-1}
\end{gathered}
$$

where:

$\mathrm{RSE}_{\mathrm{t}}$ - rate of self-employment in period $\mathrm{t}$,

$\mathrm{RNU}_{\mathrm{t}-2}-$ rate of newly registered unemployed in period ( $\left.\mathrm{t}-2\right)$,

$\mathrm{REF}_{\mathrm{t}}$ - reference cycle in period $\mathrm{t}$,

$\mathrm{RPE}_{\mathrm{t}}$ - rate of proper entrepreneurship in period $t$,

$\mathrm{RNU}_{\mathrm{t}}$ - rate of newly registered unemployed in period $\mathrm{t}$,

$\mathrm{RSU}_{\mathrm{t}-2}-$ rate of signed off unemployed in period ( $\left.\mathrm{t}-2\right)$,

$\mathrm{REF}_{\mathrm{t}-1}$ - rate of proper entrepreneurship in period ( $\left.\mathrm{t}-1\right)$,

$\mathrm{WAGE}_{\mathrm{t}-1}$ - average monthly wages in enterprise sector in period ( $\left.\mathrm{t}-1\right)$

$\mathrm{RLU}_{\mathrm{t}-4}-$ rate of long-term unemployment in period ( $\left.\mathrm{t}-4\right)$.

Results from the estimation of regression function parameters allow us to suppose that the business cycle behaves differently from the activities of self-employed persons and proper entrepreneurs. Upturns in the business cycle influence an increase in proper entrepreneur activity and a decrease in self-employed activity. Among the factors connected with the labour market, the rate of newly registered unemployed has a directly proportional influence on both groups of entrepreneurs during the business cycle, but with a different time lag. Additionally, the rate of long-term unemployment has a directly proportional impact on the rate of proper entrepreneurship, while average monthly wages in the enterprise sector have a diversely proportional impact. Cyclical changes in the rate of signed off unemployed are not a statistically significant variable.

Based on these results it can be assumed that during a recovery the number of potentially profitable business opportunities increases, and because of this the activity of proper entrepreneurs also intensifies. This increase in activity is additionally stimulated by changes in the labour market, connected with the rate of newly registered unemployed and the rate of long-term unemployment. A directly proportional relationship between these changes during the business cycle suggests that the possibilities for hiring new employees, necessary for the growth of enterprises, are greater. A diversely proportional relationship between average wages and the activity of proper entrepreneurs means that hiring workers is also connected with reduced costs. Thus, for proper entrepreneurs the situation in the labour 
market is important in the context of hiring labour capital rather than as an alternative form of occupational choice.

During a time of recovery the activity of self-employed decreases. It can be assumed that some of them become proper entrepreneurs by hiring employees, but some of them return to the labour market as paid workers.

During a depression the activity of proper entrepreneurs decreases due to the decline in business opportunities. At the same time the activity of self-employed increases, additionally stimulated by the inflow of newly registered unemployed, with a delay of about 6 months. The assumption can be made that the influx into the group of self-employed during a depression has two causes. Some self-employed persons leave the group of proper entrepreneurs by dismissing employees and some of them come from the labour market through unemployment. It can be assumed that the labour market situation fosters such alternative possibilities of occupational choice among self-employed. All these relationships are shown in the figure 1.

\section{Depression:}

decrease of proper entrepreneurship, increase of self-employment

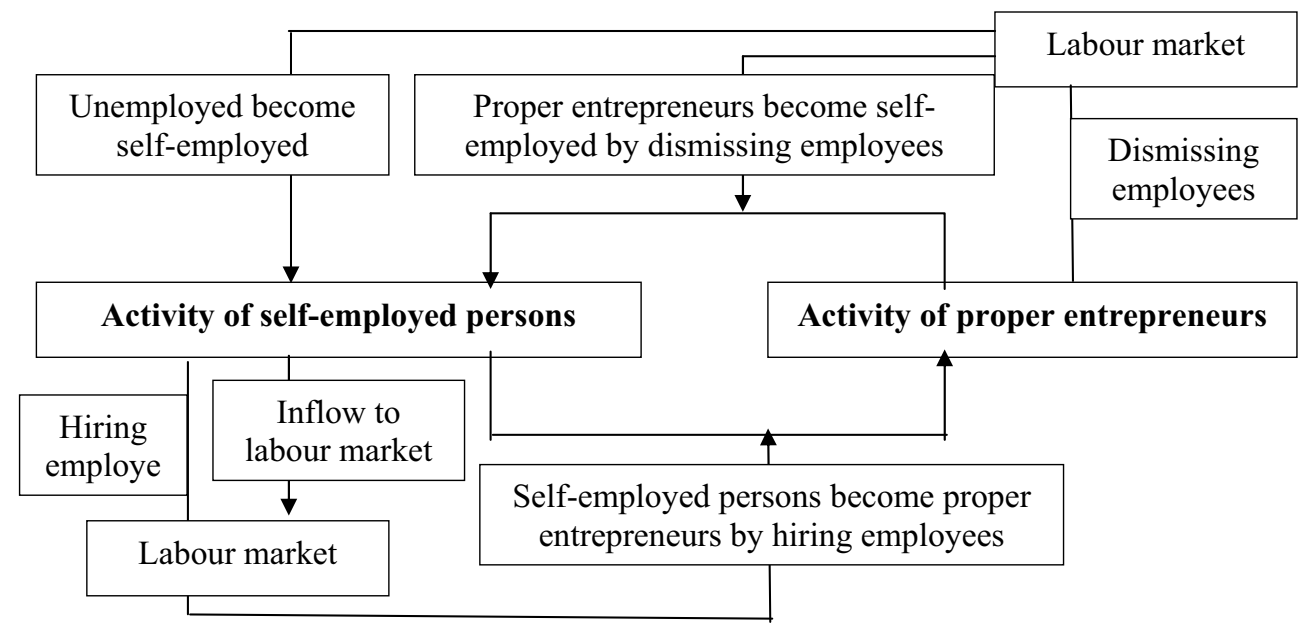

Recovery:

increase of proper entrepreneurship, decrease of self-employment

Figure 1. Changes in enterpreneurial activity during the business cycle Source: the author

To recapitulate, the dominant entrepreneurial motivation depends on the phase in the business cycle and the entrepreneurial membership. Self-employed persons are motivated by negative pressure from the labour market. Proper entrepreneurs react to the positive motivation connected with business opportunities during the business cycle. Results of research give the support to accept both hypotheses. 
Comparing the absolute values of the coefficients of regression functions, it can be observed that in each case changes in the reference cycle have the greatest impact on proper and self-employment. It can therefore be assumed that the business opportunities which appear during the business cycle influence entrepreneurial activity more strongly than pressures from the labour market. Theses findings can also be supported by the results of research connected with human capital. Entrepreneurial human capital is more important in terms of identifying opportunities than general human capital (Ucbasaran and et. 2008). This may be the reason why the influx between self-employment and proper entrepreneurship has a greater probability than the influx between entrepreneurship and paid employment.

\section{Concluding remarks}

This paper examines the relationships between the situation in the labour market and entrepreneurial activity during the business cycle. The difficulties involved in studying these relationships are caused by the fact that on the one hand, based on occupational choice theory, employment is often treated as an alternative to entrepreneurial forms of economic activity, so the situation in the labour market can provide negative motivation for undertaking entrepreneurship. On the other hand, labour is one of the production factors indispensable to an entrepreneur when running a business.

In this paper entrepreneurs are divided into two groups: self-employed people without workers; and proper entrepreneurs, entrepreneurs with paid workers. This assumption means that the reaction of self-employed persons to the labour market situation is connected to an assessment of paid work as an alternative possibility of being economically active to running their own company. For proper entrepreneurs, the situation in the labour market determines the availability and costs of hiring workers in the context of labour as a production factor. The business cycle as the time horizon for analysis is accepted in this paper. During the business cycle the number and quality of business opportunities for entrepreneurs change and the labour market situation is also different.

In this paper two hypotheses are advanced and positively verified. The cyclical changes in activity of self-employment and proper entrepreneurship react differently on the fluctuations in reference cycle, because the fluctuations of self-employment are countercyclical, and the fluctuations of proper entrepreneurship are procyclical. The cyclical changes of unemployment and wages influence on the fluctuations of self-employment as negative motivation while on the fluctuations of proper entrepreneurship as production factor.

During the business cycle there is a flux between self-employed persons and proper entrepreneurs. In a recovery phase an increase in proper entrepreneurship and a decrease in self-employment can be observed. By empoying new workers, self-employed people become proper entrepreneurs. The opposite reaction takes place during a depression phase, when there is a decrease in proper entrepreneurship and an increase in self-employment. Proper entrepreneurs, by dismmising workers, merge into the group of self-employed. At the same time, the pressures arising from the current business cycle situation seem to have a greater influence on entrepreneurial activity than the pressures from the labour market.

\section{References}

1. Abell, P., R.Crouchley, and C. Mills. 2001. Social Capital and Entrepreneurship in Great Britain. Enterprise and Innovation Management Studies 2: 119-44.

2. Acs Z.J., P. Braunerhjelm, D.B. Audretsch, B. Carlsson. 2009. The knowledge spillover theory of entrepreneurship. Small Business Economics 32: 15-30.

3. Alba-Ramirez A. 1994. Self-employment in the midst of unemployment: the case of 
Spain and the United States. Applied Economics 26: 189-204.

4. Banerjee A. V., A. F. Newman. 1993. Occupational Choice and the Process of Development. Journal of Political Economy 101: 274-98.

5. Bates T. 1985. Entrepreneur Human Capital Endowments and Minority Business Viability. The Journal of Human Resources 20: 540-54.

6. Bates T. 1990. Entrepreneur Human Capital Inputs and Small Business Longevity. The Review of Economics and Statistics 72: 551-59.

7. Bernhardt I. 1994. Comparative advantage in self - employment and paid work. Canadian Journal of Economics 27: 273-89.

8. Bird B. 1988. Implementing Entrepreneurial Ideas: The Case for Intention. Academy of Management Review 13: 442-53.

9. Blanchflower D. G. 2000. Self - Employment in OECD Countries. NBER Working Paper 7486.

10. Blanchflower D.G., A.J. Oswald. 1998. What Makes an Entrepreneur? Journal of Labor Economics 16: 26-60.

11. Blau D. M. 1987. A Time - Series Analysis of Self - Employment in the United States. Journal of Political Economy 95: 445-67. 